English law or governmental quantitative targets over the conduct of others in a wholly different jurisdiction.

Maureen McKane, Registered Mental Nurse, City Campus, Cowcaddens Road, Glasgow G1 ORA

\section{Is the fictive personality fiction?}

Sir: Chaloner (Psychiatric Bulletin, September $1999,23,589-66)$, suggests that being moved by the death of a cultural icon that you have never met, rather than by one's own suffering, may be thought of as a 'fictive personality disturbance'; a pathological process which may be a result of 'ego impoverishment' or a failure of development.

She also concludes that the mass media has encouraged this process which has "become a social norm which goes largely unremarked".

Perhaps this 'fictive personality disturbance' usually goes unremarked because it is unremarkable. A couple of thousand years ago a story went around the Middle East about the tragic death of a local hero. On hearing this tale many people found that identifying with a dead carpenter made their lives meaningful, abandoned their families and even died horrible deaths in his name (Salisbury, 1997).

Prior to the advent of the 'therapeutic state' (Szasz, 1999), Chaloner's patient might have gone to see her priest about her distress. He might have told her that identifying with others, wholly entering into their experience, with a blurring of 'as it' and reality, is part of the great Christian narrative, in which God became man. The priest would, on hearing her confession, offer absolution.

As psychiatrists we give, instead, a diagnosis. We judge her personality and find it undeveloped, 'empty', disturbed or disordered. Rather freeing her from 'sin' we burden her with what Szasz calls a 'discrediting attribute'. We offer her another 'available fiction'; a mental illness, 'an intrinsically stigmatising concept'.

\section{References}

SAusbury, J. E. (1997) Perpetua's Passion; the Death and Memory of a Young Roman Woman. London: Routledge. SzASz, T. (1999) Medical incapacity, legal incompetence and psychiatry. Psychiatric Bulletin, 23, 517-519.

Terri Eynon, Nottingham Psychotherapy Unit, St Ann's House, 114 Thorneywood Mount, Nottingham NG3 2PZ

\section{Mental health legislation}

Sir: Szasz's views (Psychiatric Bulletin, September 1999, 23, 517-519) are both illogical and barbaric.
He agrees that our speciality should operate in the same way as other specialities, but denies the existence of mental illness. I can only assume he also denies the existence of illnesses in the medical specialities of "dermatology, gynaecology etc". If this is so, it is had to understand why we need doctors at all. On the other hand, if he accepts that our patients have illnesses, as do other patients, then he must surely accept that at times our patients will be unable to make decisions for themselves, as are other patients. Any other stance is illogical.

To suggest that those with mental illnesses should always be held responsible for all their actions is nonsense. If a person loses consciousness while driving and, as a result, crosses the road into the path of an oncoming car it would seem harsh for that person to be convicted of dangerous driving. There are clearly patients who commit crimes entirely as a result of their mental illness. For such patients to receive punishment rather than treatment would be barbaric.

A. S. Zigmond, Consultant Psychiatrist, High Royds Hospital, Menston, Ilkley, West Yorkshire LS29 6AQ

\section{Royal College Golf Society}

Sir: On the last evening of the Annual General Meeting in Birmingham a small group of intrepid golfers made their way beyond the M40 to the Forest of Arden Golf Course for the inaugural meeting of the Royal College Golf Society. With the addition of a very small number of interloping general practitioners we made up a multidisciplinary band of 24 golfers all intent on a brief period of relaxation after the academic rigours of the meeting. Unfortunately we could not persuade the Continuing Professional Development office to offer us credits for sports psychology, so the altruism of all those who took part is to be applauded.

Although the weather was highly changeable all players managed to get through the round without saturation or other mishaps. The course itself was in excellent condition having been prepared for the club championship, which took place earlier that day.

The overall winner, and therefore current holder of the magnificent silver trophy, is Robert Jackson, who many readers will know as a senior member of the CPD Department in the College. We are all therefore fully anticipating treble CPD points for the next tournament.

This will take place at North Berwick Golf Club on the Friday afternoon at the end of the Annual General Meeting in Edinburgh. So if you are a 'golfer' and do not object to the company of 